\title{
An Evaluation of the Changing Nature of Power-Dependence Relations in Organizations Within the Context of the Resource Dependence Theory
}

\author{
AHMET ILHAN \\ Assistant Professor, Bayburt University, Faculty of Health Sciences, \\ Department of Health Management \\ ORCID: 0000-0003-2857-800X \\ Email: ahmetilhandr@gmail.com
}

\begin{abstract}
Resource dependence theory examines the activities carried out by locating and managing power and dependence relations, that form as a result of the relations between organizations, according to the conditional changes in the environment in which they operate. However, organizations need to develop strategies and act according to environmental changes in order to sustain their maintain their survival in their environment. At this point, within the context of resource dependence theory, on the basis of the relationship between an organization and its environment, the balance of power-based relations are crucial within the scope of their dependence on necessary resources and the struggle to obtain these resources. The main problem of this study is to consider the changing nature of power-dependence relations between organizations within the context of resource dependence theory. The theoretical discussion of power-dependence relations between organizations has been supported and explained by functional, structural, and institutional approaches. Resource dependence theory is included in functional approaches and considers an organization as a social system that tries to adapt to the conditional constraints of its environment. Accordingly, the organizations of resource dependence theory included in functional approaches are determined according to how much their performances contribute to their survival, their ability to solve organizational problems, and coalitions with various abilities and interest groups.
\end{abstract}

Keywords: Resource Dependence Theory, Power, Dependence, Environment, Organization.

\section{Introduction}

Organizations are complex structures that take action to make and implement decisions within a market economy in which they operate. This reveals the complex structures of organizations operating in many major industries in developed economies (March, 1962). In other words, organizations are structures that operate in an environment that has very large and variable qualities. The condition of these structures is related to reactions to specific environmental changes based on specific performance goals (Child, 1972). However, organizations within the social services sector in terms of the organizational population of a community faces an uncertain technology situation, resource woes, and extensive political uncertainties over the elimination of inter-organizational coordination. On the other hand, these uncertainties are often produced not by forces at the organizational level, but rather by government officials and review agencies on the financing or input side of the organization and environmental matrix (Aldrich, 1976). However, relations between the organization and the environment are one of the topics that have recently started to attract a lot of attention in the context of organizational research. Within this context, the issue of interorganizational relations is seen as a special case that can be addressed at a more general level of work about 
organizations and their environment. It is suggested that the dimensions and scope of inter-organizational relations are structures analyzed and improved within the context of the organization-environmental relations (Aldrich \& Pfeffer, 1976). Although organizational and environmental relations at the theoretical level are adaptable in many respects as a result of all this, they take into question the static consequences of the fact that precise decision-making models are involved in political coalitions of firms. In this respect, it is possible to express that certain organizational events occurred due to the nature of the coalition in the organizations (March, 1962).

Organizations face a serious struggle for survival to enhance their performance economically, socially, and politically in a competitive environment. This struggle for survival mandates that organizations gain some features. Gaining these features depends on the organization's environment, power, relation with the basic concepts of dependency, degree of interaction, and management. Within this context, organizations become power centers designed hierarchically under the assumptions of power and dependency. Hence, the importance of the relationship between the organization and the concepts of power and dependency provides a comprehensive area of study at both the theoretical and empirical levels and the organizational levels in small and large community contexts. This suggests that this is a necessary place for a systematic discussion of existing social power. In other words, it raises the issue of organizational discussion about basic assumptions related to power and dependency (Emerson, 1962).

The resources that organizations have to obtain in order to maintain their survival and continue their activities increase their degree of dependency. Within this context, the relationships between the environment, power, and dependency are variables. Accordingly, resource dependence theory has been a turning point in organizational research by offering a unified power theory at the level of organizational analysis. Pfeffer and Salancik (1978)'s classic publication "The External Control of Organizations: A Resource Dependence Perspective" has made resource dependence theory an effective and important approach in the field of organizational theory. Accordingly, this work has opened a way to the development of the resource dependence approach by using it for the first time. At the same time, the concepts of power, dependency, autonomy, and restraint are seen as inevitable in organizational research studies, as they are used in various studies. However, it has gained value as an approach that needs to be considered and investigated on resource dependency. Thus the theory of resource dependency gained strong general metaphor status and was marginalized as a basis for empirical research that could be tested within the context of theoretical progress (Casciaro \& Piskorski, 2005).

The resource dependency model is based on the premise that organizations should enter into transactions and relationships with elements that can provide the necessary resources and services in the environment if they are not able to internally produce all the resources or functions necessary to maintain their survival (Aldrich \& Pfeffer, 1976). At the same time, external resource dependency affects the internal power dynamics of organizations. Accordingly, individuals, groups, or departments are actors who can reduce uncertainty in organizations, manage significant environmental dependencies, and help the organization gain more power in order to maintain its survival and success (Pfeffer \& Salancik, 2003). Strategies developed on the basis of resource dependence theory are at the heart of Selznick's corporate theory and Emerson (1962)'s theory of change, while Pfeffer and Salancik (1978) have developed a theory about organizational responses to the restraint that have not been fully considered before.

The most obvious of these is restricted absorption. Absorbing constraints requires that the dependent actor be given the ability to control resources that create dependencies. In this way, organizations can completely resolve and eliminate restriction through mergers and acquisitions (Casciaro \& Piskorski, 2005). Paradigms developed as a result of studies in the field of organizational theory can be listed as following: transaction cost theory (Williamson, 1975), power of attorney theory (Jensen \& Meckling, 1976), new corporate theory (Meyer \& Rowan, 1977), organizational ecology theory (Hannan \& Freeman, 1977) and resource dependence theory (Pfeffer \& Salancik, 1978). Among all these paradigms developed in the field of organizational theory, it can be suggested that resource dependence theory can be considered as the most 
comprehensive paradigm within the scope of its approach to organizations. It can also be said that a power account within organizations can be combined in the context of how organizations try to manage their environment (Davis \& Cobb, 2010). However, resource dependence theory can be defined as a theory that can explain how different organizational structures emerged, why and how the multi-part form was created, why and under what conditions company mergers took place. In this respect, resource dependence theory is a general approach that claims to have a significant degree of disclosure power (Nienhüser, 2008).

Resource dependence theory is based on the fact that all organizations are critically committed to other organizations to provide them with vital resources, and this dependency is often mutual. At the same time, the theory of resource dependency formally references the inter-organizational argument for interorganizational inter-dependency to explain why independent organizations are on the path to different types of inter-organizational regulation, such as board lockdowns, alliances, joint ventures, internal resource use, mergers, and acquisitions. However, these regulations can help organizations cope with interdependencies by strengthening their autonomy and legitimacy. In this context, resource dependence theory can be used as a central explanatory approach to creating various types of inter-organizational arrangements (Drees \& Heugens, 2013).

The main problem of this study is to consider the changing nature of power-dependence relations between organizations within the context of resource dependence theory. At the same time, it has been tried to evaluate the thoughts regarding the social system in which resource dependence theory organizations take place, the source of power-dependence relation, and how it's used and managed which take place in the structural approaches. Accordingly, in the first part of the study, information about the scope of the research, its problem, and the explanation of the subjects dealt with in the study in a conceptual framework is included. In the second part, the basic assumptions of the approach to resource dependence theory are discussed. In the third part, the emphasis was made on organizational-environmental relations within the context of resource dependence theory and tried to explain these relationships that shape the behavior of organizations. The main problem of this study is to consider the changing nature of power and dependence based relations between organizations within the context of resource dependence theory. In the fifth section, there is a discussion part, which includes evaluations of the basic conceptual variables that are dealt with in terms of the assumptions of resource dependence theory. Finally, the sixth section consists of the conclusion and the section containing various suggestions in terms of guiding researchers in future studies.

\section{Resource Dependence Theory and Its Basic Assumptions}

From Weber's ([1922] 1968) ideal-typical dominant bureaucratic analysis to Burt's (1992) structural hole theory, the analysis of determinants and the consequences of power have played an important role in organization theory. However, the research on organizational power and dependency has followed not only a single developmental line but also different and contradictory approaches. These approaches are; bureaucratic structures (Gouldner, 1954; Crozier, 1964), changing political coalitions (Cyert \& March 1963), structural condition dependence and resource dependence (Hickson, et al., 1971; Pfeffer \& Salancik include opinions within the framework of 1978), organizational demographics (Kanter, 1977) and organizational networks (Burt, 1992, 1997). These various approaches have not come together in a single understanding of power and dependence. In contrast, it reflects an organizational structure consisting of various research problems and theoretical solutions that critically define the locator of organizational power, but rely on different mechanisms to explain its determinants and results (Ocasio, 2002). Pfeffer and Salancik (1978)'s book "The External Control of Organizations: A Resource Dependence Perspective" was re-published in 2003 by Stanford University's "Business Classics" series to celebrate its twenty-fifth anniversary. This book, which has become classic, has extensively discussed the approach to the full use of the concept of resource dependence and opened a way for it to take place in the literature under the name of resource dependence theory. With this book, resource dependence theory has created a scientific basis of organizational theory in the literature (Üsdiken, 2007). The ongoing influence and dissemination of 
resource dependence theory in different fields of social science were obvious in the work written by Pfeffer and Salancik (1978). In this context, resource dependence theory has a great influence on a wide range of topics such as management, sociology, education, healthcare, public policy, and other cognate disciplines. In this respect, it is possible to say that the level of benefiting from the resource dependence theory is high when examining the concept of power in terms of organizations in academic researches (Davis \& Cobb, 2010).

Resource dependence theory has become one of the most influential theories in organizational theory and strategic management since its emergence. In particular, resource dependence theory characterizes the organization as an open system dependent on external possibilities. Pfeffer and Salancik (1978) stated that in order to understand the behavior of an organization, we have to understand the context of this behavior or in other words, the environment of the organization. Resource dependence theory, on the other hand, determines the impact of external factors on organizational behavior. However, managers can take action to reduce environmental uncertainty and dependence. At the heart of these actions, there is the concept of power, which is control over vital resources (Hillman, Withers \& Collins, 2009).

The main recommendation of resource dependence theory is that organizations' survival depends on their ability to provide resources from the outside environment that are critical to their survival. So to reduce uncertainty in the flow of resources needed, organizations will try to reconfigure their dependencies with a variety of tactics. Certain tactics are one-sided; reduce interest in valuable resources, develop alternative supply sources, or pass the source of restraint by forming coalitions. Other tactics than this are based on restructuring dependencies by targeting the restrictive side in the direct relationship (Casciaro \& Piskorski, 2005). With its publication, The External Control of Organizations book emphasized three main theoretical topics that represent a change of direction in the field of organizational studies. Accordingly, it can be said that the resource dependence theory is built on these three topics. In the first and perhaps the most central topic; it was emphasized on the importance of understanding the environment or social context of organizations to understand what decisions are made, such as who to hire, the composition of boards, and what alliances and mergers should be sought.

The second important topic argues that although organizations are clearly constrained by their situation and environment, there are opportunities to make options, at least temporarily, to pool constraint resources to gain greater autonomy and the ability to pursue their interests. In the third main topic, it is argued that it is important to construct the concept of power in order to understand both intra-organizational and interorganizational behavior. In other words, the importance of social power as an idea is that constraints arising from dependency and attempts to manage or reduce restrictions emerge as an almost inevitable result of focusing on dependency as well as interdependency (Pfeffer \& Salancik, 2003).

When the relevant literature is reviewed regarding the complex functioning of organizations, it is claimed that emphasized more on the effect of internal variables such as size, technology, location, dependency on the structure of the organization, behavior patterns, and effectiveness (Negandhi \& Reimann, 1973). In this regard, organizations generally try to reduce the power of others over themselves and increase their power over others. Pfeffer (1987) expressed the main argument of the resource dependency approach and interorganizational relations as follows. According to this; (1) Organizations are the basic units for understanding intercompany relations and society; (2) These organizations do not have the autonomy but are limited by a network of interdependence with other organizations; (3) Interdependence, combined with uncertainty about what actions the organizations depend on, leads to a situation in which survival and success are uncertain; (4) Organizations, therefore, take actions to manage external interdependencies, although inevitably they are never fully successful and produce new and interdependent patterns; and (5) When these dependency patterns have some effect on organizational behavior, they generate interorganizational and intra-organizational power (Hillman, et al., 2009). 
Pfeffer (2003) stated in his book that the resource dependence theory was initially an approach developed to bring an alternative perspective to the theories of economic mergers and board lockups and to fully understand the nature of inter-organizational relations that play an important role. However, he stated that the motives of those who run the organization are to ensure the survival of the organization and develop their autonomy while as well as maintaining stability in their relations. So these are the driving forces behind many of the actions the organization takes. In addition, power often has a dominant feature in making strategies. Within this context, the resource dependence theory has three basic recommendations. Accordingly; (1) Social context is important; (2) Organizations have strategies to increase their autonomy and to pursue their interests; and (3) Power is crucial not only in terms of rationality or efficiency but also in understanding the internal and external actions of organizations. Within this context, the emphasis on power and the careful expression of the clear tactical ways available for organizations discriminate power from other approaches as a distinctive feature of the resource dependence theory (Davis \& Cobb, 2010). At the same time, resource dependence theory emphasizes that most organizations face numerous levels of incompatible demands from various external actors. However, resource dependence theory tends to emphasize the task environment and addresses the impacts of the social environment of organizations and state pressure on organizations. Resource dependence theorists point to the organizational necessity of adapting to environmental uncertainty, dealing with problematic interdependencies, and actively managing or controlling resource flows. Within this context, the resource dependence theory focuses on a wide variety of active choice behaviors that organizations can apply to manipulate external dependencies or to allocate critical resources or to be effective on the resources in question (Oliver, 1991).

Resource dependence theory suggests that organizations are influenced and constrained by their environments and try to manage their resource dependence by creating different forms of interorganizational regulation. In this respect, according to resource dependence theorists, inter-organizational arrangements are seen as tools necessary to reduce power imbalances and manage interdependencies between the organization and its parties on critical resources. We can state that implementing such regulations in question will allow organizations to determine their boundaries (Drees \& Heugens, 2013).

Table 1: Assumptions of Resource Dependence Theory

\begin{tabular}{|l|l|}
\hline \multicolumn{1}{|c|}{ Explanatory Factors } & \multicolumn{1}{c|}{ Resource Dependence Theory } \\
\hline \multirow{3}{*}{ Context of Organizational Behavior } & - Business environment \\
& - Active preference behavior \\
& - Coping with mutual dependencies \\
& - Visible pressure \\
& - Harmony \\
& - Limited resources management \\
& - Reducing uncertainty \\
& - Power and influence \\
\hline \multirow{3}{*}{ Motives of Organizational Behavior } & - Resource mobilization \\
& - Control of external factors \\
& - Political and calculating interests \\
& - Discord self-service \\
& \\
\hline
\end{tabular}

Source: Oliver, 1991, p. 147; Koç \& Say1lar, 2016, p. 142-143

Table 1 summarizes the basic assumptions of resource dependence theory in terms of context and motivation factors. Accordingly, within the context of resource dependence theory, it's focused on the structures of strategic responses to external pressures and expectations. Context and motive factors help to identify various points in resource dependency assumptions and the potential of resource dependency estimates of the strategy to be developed at the organizational level. On the other hand, these factors highlight the basic assumptions about organizational behavior that organizations must adopt in order to 
correct their perspectives, such as adaptation and diversity at various levels. These assumptions include the potential to change in the terms of choice, awareness, proactivity, coping with interdependencies, influence, and self-interest that organizations exhibit in response to environmental constraints (Oliver, 1991). As a result of all this, the basic assumption of resource dependence theory is based on the assumption that dependency on critical and important resources affects the actions of organizations and that organizational decisions and actions can be explained depending on the level of dependency. Within this context, it is possible to say that Pfeffer and Salancik tried to systematize and integrate all their theoretical ideas and empirical results in a single comprehensive theoretical approach in resource dependence theory (Nienhüser, 2008).

\section{Organization-Environment Relations within the Context of Resource Dependence Theory}

In the organizational theory literature, the importance of the environment for organizations has been recognized with the introduction of open system concepts and models. According to Bertalanffy (1956), the concept of an open system emphasizes the interdependencies that relate to an organization and its surrounding elements. Burns and Stalker (1961), Emery and Trist (1965), Lawrence and Lorsch (1967), and Aguilar (1967) have been the first participants to adopt this way of thinking. Therefore, the concept of the environment means the environment in which organizations operate. In other words, there are several different concepts used to define specific sectors for the environments in which organizational activities are carried out. These concepts can be listed as following; task environment Dill (1958), field Levine and White (1961), region Child (1972), lower environment Lawrence and Lorsch (1967), or industry Porter (1980). Within this context, we can say that there are different perspectives in organization-environment thought (Frishammar, 2006).

The environment represents a wider sphere in which organizations operate. In this respect, the environment has a characteristic that represents many things for the organization. These features consist of components such as resources, other organizations, organizational networks, existing and emerging exchange relations between organizations, dependency, and uncertainty. Environment and the set of given data deal with the distribution of power within the organization with a function that defines and limits it, as well as its the organization's recognized areas, resource availability and needs, the level of autonomy in the environment, internal business processes, and procedures.

To minimize the constraints imposed by the environment, strategic decisions are made by the leaders of the organization in an attempt to increase the certainty about the flow of the resources which are necessary to the organization, reduce dysfunctional dependency relationships shared with the other organization and ultimately increase organizational autonomy within its environment. These decisions result in the continuation of various buffering and bridging activities (Johnson, 1995).

Within the scope of resource dependence theory; organizations are dependent on a resource environment that can impose harmful constraints and create uncertainty for organization-centered structures. According to Pfeffer and Salancik (1978); the environment has three basic structural features. These; (1) Density; wide dispersion of power and authority in the environment (2) Generosity; the availability or scarcity of critical resources; and (3) Interdependence; It is the number and pattern of links between organizations.

These three structural features, in turn, determine the relationships between social actors, especially the conflicts present in the social system and the degree of interdependence. As a result of these, conflict and interdependence determine the uncertainty faced by the organization (Davis \& Powell, 1992). Accordingly, within the framework of resource dependency theory, the links between organization-environment relations and organizational actions are shown in figure 1. 
Figure 1: The Relationships Between Environment, Organization and Organizational Actions

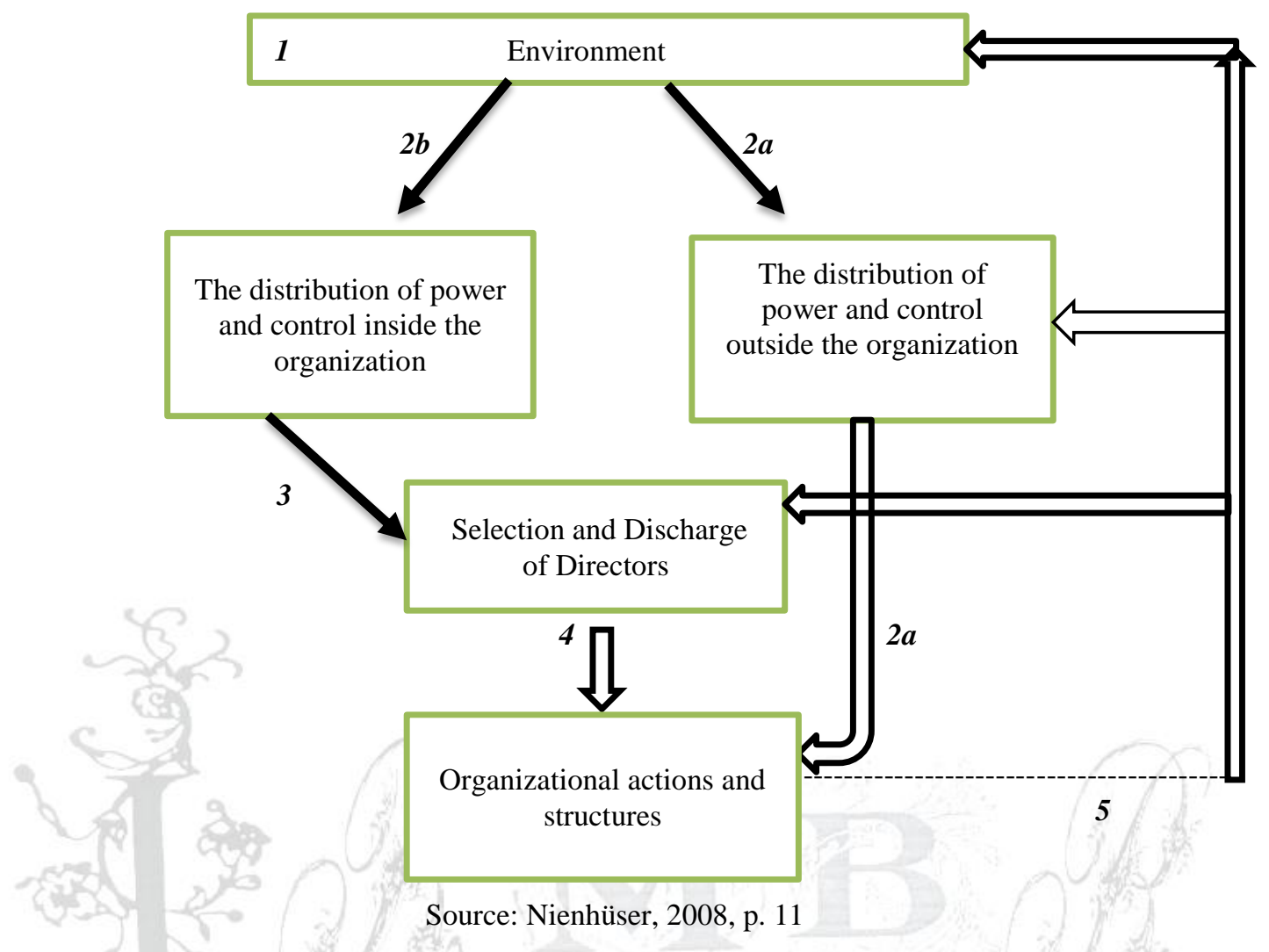

An adaptation of a diagram of Pfeffer and Salancik (2003) is shown in figure 1 in order to understand and analyze the Resource Dependence theory more closely. While the diagram in question provides a framework for organization-environment relations, it does not offer any causal proposition. Accordingly, in the diagram of Pfeffer and Salancik (2003), 2a, the distribution and control of power outside the organization variable is expanded with the relation number 5. Thus, it is claimed that the whole picture is explained better within the context of resource dependence theory with the modified diagram (Nienhüser, 2008). At the same time, theory and research focusing on the environmental effects of on organizations are found at all the five levels involved in the analysis of organizations. These five levels of analysis It consist of (1) Members, (2) Sub-units, (3) Individual organizations, (4) Populations of organizations, and (5) Organizational communities. Well-known analyzes of the effects of the studies aimed at explaining the organizational field. Within this context, the most common focus is to deal with the organization and its environment. In fact, this choice is quite common and reveals an implied understanding that individual organizations are appropriate units for the study of the organization-environment relationship (Hannan \& Freeman, 1977).

In the environments in which organizations operate, their efforts to survive and their need to succeed wouldn't risk their existence. At this point, if stable supplies were provided for the needed resources or the resources needed by the organization would be constantly available, then there would be no problems. However, these problems arise not only because organizations are dependent on their environment but also because of the unreliability of this environment. Therefore, the environment may change and new organizations may enter and exit this environment and the supply of resources may become very scarce. In this regard, when the environment changes, organizations face the possibility of not surviving or changing 
their activities in response to these environmental changes (Pfeffer \& Salancik, 2003). On the other hand, resource dependence theory, developed by various researchers such as Pfeffer and Salancik (1978), Aldrich and Pfeffer, (1976), takes a more detailed view of existing organizations by looking at the resource dependencies of other organizations. In this context, Jacobs (1974) and Pfeffer and Salancik (1978) defined environmental dependence as the importance of a resource for the organization and the number, diversity, and relative power of organizations competing with the number of resources for which the resource is available. Pfeffer and other researchers have suggested that the various strategies organizations can use to reduce outsourcing dependency vary systematically according to the types and degrees of dependencies. The dimension and the composition of boards of directors (Pfeffer, 1972a, 1973), merger and joint venture activity (Pfeffer, 1972b; Pfeffer \& Nowak, 1974), and executive recruitment and succession (Pfeffer \& Leblebici, 1973) can be given as examples for this case (Dess \& Beard, 1984).

Resource dependence theory argues that the dependence models of the organization on resources from the environment lead to the constraint and control of the organization from outside. Therefore, the theory tries to explain organizational behavior patterns by referring to environmental dependency patterns (Davis \& Powell, 1992). This point of view and the proposition that organizations should react to the external environment reached an important position that should be evaluated and analyzed in the field of organizational theory and strategic management (Hillman, et al., 2009). Accordingly, in the context of resource dependency theory, organizations need to react to changes in the environment in which they operate in order to obtain the resources they need to survive. It is possible to say that the level of these reactions depends on the relations of the organization with its environment and the quality of the strategic decisions it takes. In this framework, the relationship between organization and environment is shown in figure 2 .

Figure 2: Organization-Environment Relationships in the Context of Resource Dependence Theory

\begin{tabular}{|c|c|c|}
\hline $\begin{array}{l}\quad \text { Environment } \\
\text { - Resources } \\
\text { - Distribution of resources } \\
\text { - Organizational networks } \\
\text { - Current and emerging } \\
\text { inter-organizational } \\
\text { exchange } \\
\text { relationships (dependence, } \\
\text { reciprocity or } \\
\text { domination relations) } \\
\text { - Ambiguity } \\
\text { - Other }\end{array}$ & $\begin{array}{l}\text { Organization } \\
\text { - Recognized area } \\
\text { - Resource needs } \\
\text { - The possessed autonomy in } \\
\text { the environment } \\
\text { - Shared relationships with } \\
\text { other organizations } \\
\text { - Operating processes / } \\
\text { procedures } \\
\text { - Distribution of the } \\
\text { organizational structure } \\
\text { - the dominant coalition and } \\
\text { power distribution } \\
\text { - Other }\end{array}$ & $\begin{array}{l}\text { Strategic Decisions of the } \\
\text { Organization } \\
\text { - Guaranteeing the critical } \\
\text { resource flow } \\
\text { - Reducing the functionless } \\
\text { dependencies } \\
\text { - Increasing the } \\
\text { organizational autonomy } \\
\text { through environmental } \\
\text { limitations }\end{array}$ \\
\hline
\end{tabular}


The resource dependence theory and the general logic of the organization-environment relationship from the perspective of a particular organization within the framework of the organization-environment and the strategic decisions taken by the organization are shown in Figure 2. The context of the organization is the environment in which it operates. However, the environment in which the organization is located is of great importance in terms of many variables. These variables are; resources, distribution of resources, organizational networks, existing and emerging exchange relations between organizations and uncertainty. Depending on the position of inter-organizational power and various factors the organization has in its environment, various strategies are developed by organizational decision makers and these strategic decisions affect the dynamics and relationships made in the environment. Therefore, organizationenvironment relationships exhibit a dynamic feature in terms of process. Within this context, the concepts and processes shown in Figure 2 enable us to have an idea about the functioning of the resource dependence approach from an organization-environment perspective, its relations, and general logic (Johnson, 1995). If we summarize the organization-environment relations within the context of resource dependence theory, Bourgeois (1980), Frishammar (2006), Cannon and St John (2007) accepted that the organizational environment has an important role in affecting the survival and development abilities of organizations (Singh, Power \& Chuong, 2011). In general, it is stated in the literature that the environment is divided into three categories. These were defined as (1) object, (2) quality, and (3) perception. Dill (1958), who sees the environment as objects, proposed a two-level classification. These are classified in terms of mission environment and general environment. Mission environment consists of customers (distributors and users), suppliers (materials, labor, equipment, capital and workplace), competitors (for both markets and resources), and regulatory groups (government agencies, trade unions, and international associations) (Bourgeois, 1980). On the other hand, the general environment consists of multitasking environments that are the sources of general social, political, economic, demographic, and technological trends (Singh, et al., 2011). Environment restricts actions objectively according to the number of resources available. In other words, the distribution of resources in the environment should be perceived subjectively and interpreted by managers. In this respect, the concept of constraint has the feature of explaining why individuals take into account relatively small differences in the performance and activities of organizational systems (Nienhüser, 2008).

However, members of organizations competing in a dynamic industry will be more likely to segment the homogeneous elements of their environment in order to cope with uncertainty. At this point, Thompson (1967) expressed dealing with uncertainty as the basis of the process that emerged administratively. Organization theory, labor policy, and industrial organization literature suggest organizational strategies and tactics such as buffering, collusion, long-term contracts, and vertical integration to create a more predictable environment. As a result of all these, it is possible to say that uncertainty is a factor that affects organizational structure. Accordingly, it can be argued that as task uncertainty increases, more information level should be processed among decision makers in order to reach a certain performance level (Dess \& Beard, 1984).

\section{The Changing Nature of Power and Dependency Relations in the Context of Resource Dependence Theory}

In organizational studies, typically research designs treat power as an independent variable. Within this context, power has been used in community work to explain decisions about community programs, resource allocation, and voting behavior. It has been used in organizational studies to explain decision making and morale and alienation, especially in small groups (Hickson, Hinings, Lee, Schneck \& Pennings, 1971). On the other hand, dependence leads to the development of the relations between organizations as a result of the organization's need to obtain resources. However, the unequal distribution of needed resources results in interdependent organizational relations. Therefore, the need to obtain resources for an organization reveals dependence relations between an organization and another. Factors determining the level of dependence in question can be listed as the importance of resources for the organization, the 
relative scarcity of resources, and the degree to which the resources are available in the environment (Johnson, 1995).

Social relationships often require bonds of interdependence between the parties. A is dependent on B if it wants to have goals and satisfactions that simplify its success. Likewise, due to interdependence, it is more or less imperative for both parties to be able to control or influence the other's behavior. These relations of interdependence mean that both parties are in a position to accept or deny or facilitate or hinder the satisfaction of the other to a certain extent. In this respect, it can be stated that the ability of one of the parties to control or influence the other has control over the things that they value and can take place in a wide range depending on the relationship in question. Therefore, power is implicitly in the dependence of the other party (Emerson, 1962).

Given the view that power is context or relationship-specific (Pfeffer, 1981a), organizational power and dependence is a situation related to the power of individuals and groups according to their relations with the organization and how dependent they are on it. As a result, by adapting Weber's ([1922] 1968) definition of power to the organizational level, it is possible to express organizational power as the ability to influence organizational actions and results despite the resistance of individuals and groups (Ocasio, 2002). It is possible to evaluate the conditions in which an organization focuses on a model to deal with environmental uncertainty, power, and dependencies. According to Pfeffer and Salancik (1978), (1) The context of unexpected situations, uncertainties, and interdependencies, and the environmental context affect the distribution of power and control within the organization, (2) The distribution of power and control within the organization affects the tenure and selection of large organizational managers, (3) Organizational policies and structures, power and (4) Managers who control organizational activities affect these activities and the resulting structures (Hillman, et al., 2009). However, actors who control a large part of the critical resources at the organizational level but do not need any resources from the organization themselves are relatively strong. As a result, the actors in question will desire to make high demands from the organization. The more dependent an organization is, the higher the amount of uncertainty it is and therefore the more it tries to reduce uncertainties. The importance of management emerges at this point. Accordingly, the behavior of management is neither completely determined by the environment, nor is the role of management irrelevant as in ecological population theories, where for blind mutations are reduced to only one cause. According to Pfeffer and Salancik (2003), management is not just an actor that tries to maximize profit or make rational strategies. At the same time, the management has a function of decision making and legitimation as well as a function of taking responsibility (Nienhüser, 2008).

It is suggested that it is possible to consider organizational power and dependence theories in three approaches in order to understand and evaluate them. These approaches are listed in functional, structural, and institutional forms. These three approaches to organizational power and dependency have different basic assumptions about the nature of organizations, sources of power, and consequences. Accordingly, functional (functional) power theories emphasize how the needs of organizations to survive and adapt to their environment affect the strength of individuals and groups within organizations. Structural theories explain how the distribution of power within organizations is embedded in the structure of social relations inside and outside of organizations. Institutional theories emphasize how organizational power is included in the official rules, normative commitments, and cultural structure that characterize the organization and its institutional environment (Ocasio, 2002). However, it may be thought that the resource dependence theory should be supported and explained more by functionalist approaches such as the transaction cost economics or the agency theory that is dominant when cynicism is low (Davis \& Cobb, 2010). Within this context, resource dependence theory is included in functional approaches among the approaches made regarding organizational power and dependence. Accordingly, the functional approach considers organizations as social systems that try to adapt to their environment. These social systems are made up of organizations, their various goals, interest groups with specific abilities, and organizational sub-units. According to the functional approach in which resource dependence theory is included; the strength of 
individuals and groups is determined by their level of contribution to the performance and survival of organizations and their ability to solve organizational problems objectively (Ocasio, 2002).

With a kind of power based on the control of critical resources, organizations can make various demands that threaten the long-term survival of the central organization by imposing restrictions on their future actions. In this case, the central organization can respond to these requests in two ways. (1) It can respond through adaptation or accommodativeness (2) avoiding or managing the effects of the Initiative. Pfeffer and Salancik (1978) quoted conditions that facilitate adaptation. These conditions are summarized as follows. Pfeffer (1985); when power is asymmetrical and the external organization has the legitimate right to use it, and also when the behavior of the central organization is under its control and observable, it seems likely that external control efforts will be attempted and successful (Davis \& Powell, 1992). Considering the applicability of the understanding developed regarding organizations regarding the resource dependency theory, it is possible to say that the power levels occurring between organizations within any organizational set, network, or field will actually differ from each other. So although it is difficult to assume how strong or weak any organization is, it is reasonable to assume that organizations find themselves closer to one level than another. In the light of all these, it can be said that resource dependence theory can provide a useful framework for explaining these differences (Johnson, 1995).

Within the context of resource dependence theory, the balance of power, and interdependence should be considered together in order to produce a theoretically comprehensive structural description of power and dependence structure in the context of bilateral relations between organizations. This is because, for any value of power imbalance, power-based dependence relations can be characterized by varying levels of interdependence. Otherwise, in the case of any interdependence level, different levels of power imbalance may occur. Accordingly, the configurations of power imbalance and interdependence relations among organizations are shown in Table 2 (Casciaro \& Piskorski, 2005).

Table 2: Configurations of Power Unbalance and Interdependence

\begin{tabular}{|c|c|c|c|c|}
\hline & & Low (1) & Medium (2) & High (3) \\
\hline \multirow{3}{*}{$\begin{array}{c}X \text { 's } \\
\text { Dependence } \\
\text { to } Y\end{array}$} & High & $\begin{array}{l}\text { Configuration: } 7 \\
\text { Balance of Power: } 2 \\
\text { Mutual Dependence: } 4\end{array}$ & $\begin{array}{l}\text { Configuration: } 8 \\
\text { Balance of Power: } 1 \\
\text { Mutual Dependence: } 5\end{array}$ & $\begin{array}{l}\text { Configuration: } 9 \\
\text { Balance of Power: } 0 \\
\text { Mutual Dependence: } 6\end{array}$ \\
\hline & $\begin{array}{l}\text { Moderate } \\
\text { (2) }\end{array}$ & $\begin{array}{l}\text { Configuration: } 4 \\
\text { Balance of Power: } 1 \\
\text { Mutual Dependency: } 3\end{array}$ & $\begin{array}{l}\text { Configuration: } 5 \\
\text { Balance of Power: } 0 \\
\text { Mutual Dependence: } 4\end{array}$ & $\begin{array}{l}\text { Configuration: } 6 \\
\text { Balance of Power: } 1 \\
\text { Mutual Dependence: } 5\end{array}$ \\
\hline & $\begin{array}{c}\text { Low } \\
\text { (1) }\end{array}$ & $\begin{array}{l}\text { Configuration: (1) } \\
\text { Balance of Power: } 0 \\
\text { Mutual Dependence: } 2\end{array}$ & $\begin{array}{l}\text { Configuration: } 2 \\
\text { Balance of Power: } 1 \\
\text { Mutual Dependency: } 3\end{array}$ & $\begin{array}{l}\text { Configuration: } 3 \\
\text { Balance of Power: } 2 \\
\text { Mutual Dependence: } 4\end{array}$ \\
\hline
\end{tabular}
Source: Casciaro \& Piskorski, 2005, p. 171

Table 2 shows the three potential dependence levels of each actor (organization) on the other. Accordingly, the pair shown in the shaded boxes indicates balanced power relationships. In the binary in the white cells, power relations are unstable and power imbalance levels are symmetrical around the diagonal. In case of power imbalance above the diagonal, the actor prefers $\mathrm{Y}$, while in case of power imbalance below the diagonal, the actor prefers $\mathrm{X}$. However, equal levels of power imbalance shape many pairs, while different levels of interdependence distinguish them. Accordingly, both configurations 1 and 9 on shaded boxes are power balanced. In contrast, configuration 9 shows higher interdependence than configuration 1 . In Configuration1, the actors exert minimal power against each other because they are not dependent on each other either because they have the resources that are necessary for the survival of X and Y, or because both actors have a large number of alternative resource providers. In contrast, in configuration 9 , both actors $X$ and $\mathrm{Y}$ exert significant levels of power against each other as they depend on each other in terms of obtaining necessary resources or have only a few alternative providers of those resources. Therefore, when 
the dependence level of an actor changes and the dependence level of the other actor is kept constant, both the power balance and interdependence levels between them changes. Thus, it can be said that the levels of the balance of power and interdependence relations have the effect of determining the structural conditions in which an actor can restructure dependencies (Casciaro \& Piskorski, 2005). Within the context of resource dependence theory, it is possible to express all social relations that exist among organizations within the framework of power and dependency relations. Within this context, in bilateral relations between organizations, it is seen each one tries to keep the other's dependence on it. Hence the nature of this common function is dependence; It is possible to express the dependence of organization A on organization $\mathrm{B}$ in the form of (1) A being directly proportional to the motivational investment made in the goals mediated by B, and (2) Inversely proportional to the appropriateness of these goals to A except A and B relation. On the other hand, if the dependence of one party is the basis of the power of the other in interorganizational relations, then this power should be defined as a potential effect. Accordingly, power can be defined as the strength of organization A to organization B and the amount of resistance that B could potentially be overcome by A (Emerson, 1962). In relations between organizations, if the direction of dependency is determined by the power imbalance, power itself must be considered separate from these foundations. At this point, if power is the determination of A's behavior by B, then power, regardless of whether one, any or all species are included; it will be accepted as a legitimate or normative expected part of power by some role descriptors (Hickson, et al., 1971). Therefore, within the context of resource dependence theory, it is possible to say that the relationships between inter-organizational power and dependence variables show a varying feature depending on the difference levels.

\section{Conclusion}

Resource dependence theory can be expressed as a theory that sees an organization as a social system, deals with the struggles of organizations on the basis of organizational and environmental relations, and tries to explain the balance of power and dependence levels at the point of obtaining the resources necessary for their survival. Resource dependence theory is accepted as an approach that contributes to the field of organization theory at a stimulating and inspiring level. In particular, the events that have taken place in the forty years since the first publication of the classic "The External Control of Organizations: A Resource Dependence Perspective" by Pfeffer and Salancik (1978) have changed both the sources of organizational power and dependence and their management tools. Therefore, as long as power relations play an important role in the conduct of organizational life, resource dependence theory will continue to be beneficial and guiding (Davis \& Cobb, 2009). Within this context, although there are numerous approaches to researches related to organizational power and dependence (Emerson, 1962; Casciaro \& Piskorski, 2005; Ocasio, 2002), power and dependence relations are generally supported by functional, structural and institutional approaches as well as resource dependence theory (Ocasio, 2002). Therefore, we can say that organizational power and dependence relations take place as an explanatory variable produced by social relations in organizational research at the theoretical level. However, it is possible to say that addressing the determinants of the balance of power and dependence levels will contribute to both inter-organizational relations and the field of organizational theory.

In this study, the relevant literature about resource dependence theory was examined in detail and the level and changing characteristics of power and dependence based relations within the framework of organization-environment relations were tried to be addressed from various aspects. Moreover, the application areas of activities such as buffering and bridging mechanisms that can be applied against the balance of power relations between organizations and degrees of dependence are mentioned. At the same time, it has been determined that organizational strategies such as buffering, collusion, long-term contracts, and vertical integration can be developed and implemented in order to reach critical resources against industrial environmental uncertainties, manage dependencies and fight within the framework of power imbalance relations and create a more specific and predictable environment in the field of organizational theory (Dess \& Beard, 1984). Within this context, it is expected that the theoretical knowledge obtained will be useful in the field of organizational theory both in terms of developing the theory and in terms of 
guiding future studies in this field. Within the context of resource dependence theory, it can be said that the imbalance that occurs as a result of power relations on the basis of organization-environment relations will vary with the scale between the parties. However, it is possible to say that organizations will gain a static identity in terms of power at this stage, as the imbalances in power relations vary according to the scale between the parties. Therefore, we can say that the resource dependence theory approach takes place as a functional approach and has a static nature in terms of power balance. In the resource dependence approach, power-dependency relations generally focus on the potential effects and quality of the power organizations can use in the face of environmental uncertainties. Within the framework of resource dependence theory, the change in the way of doing business, employees, managers, strategies, and actions to be implemented can be evaluated as a mechanism of the relations between the environment in which the organization operates and the degree of power and dependency it has. The resource dependency theory discussed in this context is largely included in the interdependence relations that connect the balance of power in inter-organizational relations as a social system within the functional approach. Therefore, the basic value of the relationship in question can be expressed as bringing together the various organizational activities at the social level such as the internalization of power and dependency relations, organizational performance, and the changing characteristics of organizations.

It is possible to say that the resource dependence theory generally has a characteristic that tries to explain the behavior, structure, stability of existence, power, dependence on resources, and change of organizations in the environment in which they operate. Within the framework of resource dependence theory, we can say that organizations can make a significant contribution to making healthier organizational decisions with mechanisms such as substitution in terms of organizational resources, developing strategic alliances, and long-term contracts in an environment with uncertain power relations and dependency on critical resources. Finally, according to the resource dependency approach, it is possible to say that the power imbalance and dependency relations have a characteristic that varies according to uncertain environmental conditions. However, we can state that resource dependency is discussed within the scope of the functional structure in terms of the organization's different goals, abilities, interests and the survival and adaptation needs of organizations affect organizational actors at different levels and therefore the active role that organizations play in this process.

\section{References}

Aguilar, F. (1967). Scanning the business environment. New York: Macmillan.

Aldrich, H. (1976). Resource dependence and interorganizational relations: Local employment service offices and social services sector organizations. Administration \& Society, 7(4), 419-454.

Aldrich, H. E., \& Pfeffer, J. (1976). Environments of organizations. Annual Review of Sociology, 2, 79-105.

Bertalanffy, L. V. (1956). General system theory. In General systems (Yearbook of the society for the advancement of general systems theory), (Eds). L. von Bertalanffy and A. Rapoport, 1-10. Ann Arbor: Baum-Brumfield.

Bourgeois, L. J. (1980). Strategy and environment: A conceptual integration. Academy of Management Review, 5(1), 25-39.

Burns, T., \& Stalker, G. M. (1961). The management of innovation. London: Tavistock.

Burt, R. S. (1992). Structural holes: The social structure of competition. Cambridge, MA: Harvard University Press.

Burt, R. S. (1997). The contingent value of social capital. Administrative Science Quarterly, 42, 339-365.

Cannon, A.R., \& St John, C. (2007). Measuring organizational complexity: A theoretical and empirical assessment. Organizational Research Methods, 10(2), 296-321.

Casciaro, T., \& Piskorski, M. J. (2005). Power imbalance, mutual dependence, and constraint absorption: A closer look at resource dependence theory. Administrative Science Quarterly, 50(2), 167-199.

Child, J. (1972). Organizational structure, environment and performance: The role of strategic choice. Sociology, 6(1), 1-22.

Crozier, M. (1964). The bureaucratic phenomena. Chicago: University of Chicago Press. 
Cyert, R. M., \& March, J. G. (1963). A behavioral theory of the firm. Englewood Cliffs, NJ: Prentice-Hall.

Davis, G. F., \& Cobb, J. A. (2010). Resource dependence theory: Past and future. Research in the Sociology of Organizations, 28, 21-42 (p.1-31).

Davis, G. F., \& Powell W. W. (1992). Organization-environment relations. In Dunnette ve Hough L.M. (Eds.), Handbook of industrial and organizational psychology, 315-376. Palo Alto: Consulting Psychologists Press.

Dess, G. G., \& Beard, D. W. (1984). Dimensions of organizational task environments. Administrative Science Quarterly, 29(1), 52-73.

Dill, W. (1958). Environment as an influence on managerial autonomy. Administrative Science Quarterly 2(3), 409-443.

Drees, J. M., \& Heugens, P. P. M. A. R. (2013). Synthesizing and extending resource dependence theory: A meta-analysis. Journal of Management, 39(6), 1666-1698 (p.1-33).

Emerson, R. M. (1962). Power-dependence relations. American Sociological Review, 27(1), 31-41.

Emery, F., \& Trist, E. (1965). The casual texture of organizational environments. Human Relations, 18(1), 21-32.

Frishammar, J. (2006). Organizational environment revisited: A conceptual review and integration. International Studies of Management \& Organization, 36(3), 22-49.

Gouldner, A. (1954). Patterns of industrial bureaucracy. Glencoe, IL: Free Press.

Hannan, M. T., \& Freeman, J. (1977). The population ecology of organizations. American Journal of Sociology, 82(5), 929-964.

Hickson, D. J., Hinings, C. R., Lee, C. A., Schneck, R. E., \& Pennings, J. M. (1971). A strategic contingencies' theory of intraorganizational power. Administrative Science Quarterly, 16(2), $216-229$.

Hillman A. J., Withers M. C., \& Collins, B. J. (2009). Resource dependence theory: A review. Journal of Management, 35(6), 1404-1427.

Jacobs, D. (1974). Dependency and vulnerability: An exchange approach to the control of organizations. Administrative Science Quarterly, 19, 45-59.

Jensen, M. C., \& Meckling, W. H. (1976). Theory of the firm: Managerial behavior, agency cost, and ownership structure. Journal of Financial Economics, 3, 305-360.

Johnson, B. L. (1995). Resource dependence theory: A political economy model of organizations. Salt Lake City, USA: University of Utah, Educational Resource.

Kanter, R. M. (1977). Men and women of the corporation. New York: Basic Books.

Koç, O., \& Sayılar, Y. (2016). Örgüt araştırmalarında kaynak bağımlılı̆̆ı perspektifi: Kuramsal bir değerlendirme. İ. Ü. Işsletme Fakültesi İktisadı Enstitüsü Yönetim Dergisi, 27(80), 136-177.

Lawrence, P., \& Lorsch, J. (1967). Organizations and environment. Cambridge: Harvard University Press.

Levine, S., \& P. White. (1961). Exchange as a conceptual framework for the study of inter-organizational relationships. Administrative Science Quarterly, 5(3), 583-601.

March, J. G. (1962). The business firm as a political coalition. The Journal of Politics. 24(4), 662-678.

Meyer, J. W., \& Rowan, B. (1977). Institutionalized organizations: Formal structure as myth and ceremony. American Journal of Sociology, 83, 41-62.

Negandhi A. R., \& Reimann, B. C. (1973). Correlates of decentralization: Closed and open systems perspectives. The Academy of Management Journal, 16(4), 509-514.

Nienhüser, W. (2008). Resource dependence theory-how well does it explain behavior of organizations?. Management Revue, 19(1/2), 9-32.

Ocasio, W. (2002). Organizational power and dependence. In J. A. C. Baum (Ed.), Blackwell companion to organizations, 363-385. Oxford: Blackwell.

Oliver, C. (1991). Strategic responses to institutional processes. Academy of Management Review, 16(1), 145-179.

Pfeffer, J., \& Salancik, G. R. 1978. The external control of organizations: A resource dependence perspective. New York: Harper \& Row.

Pfeffer, J., \& Salancik, G. R. 2003. The external control of organizations: A resource dependence perspective. Stanford, CA: Stanford University Press. 
Pfeffer, J. (1972a). Size and composition of corporate boards of directors. Administrative Science Quarterly, 17, 218-229.

Pfeffer, J. (1972b). Merger as a response to organizational interdependence. Administrative Science Quarterly, 17, 382-394.

Pfeffer, J. 1973. Size, composition, and function of hospital boards of directors: A study of organizationenvironment linkage. Administrative Science Quarterly, 18, 349-364.

Pfeffer, J. (1987). A resource dependence perspective on interorganizational relations. In M. S. Mizruchi, \& M. Schwartz (Eds.), Intercorporate relations: The structural analysis of business, 22-55. Cambridge, UK: Cambridge University Press.

Pfeffer, J. (1981). Power in organizations. Marshfield, MA: Pittman.

Pfeffer, J. (1985). Organizations and organization theory. In G. Lindzey \& E. Aronson (Eds.), The handbook of social psychology (3rd ed.). New York: Random House.

Pfeffer, J., \& Leblebici, H. (1973). Executive recruitment and the development of interfirm organizations. Administrative Science Quarterly, 18, 445-461.

Pfeffer, J., \& Nowak, P. (1974). Joint ventures and interorganizational interdependence. Administrative Science Quarterly, 21, 398-418.

Porter, M. (1980). Competitive strategy. New York: Free Press.

Singh, P. J., Power, D., \& Chuong, S. C. (2011). A resource dependence theory perspective of ISO 9000 in managing organizational environment. Journal of Operations Management, 29, 49-64.

Thompson, J. D. (1967). Organizations in action. New York: McGraw-Hill.

Üsdiken, B. (2007). Çevresel baskı ve talepler karşısında örgütler: Kaynak bağımlılı̆̆ı yaklaşımı. In A. S. Sargut, \& Ş. Özen (Eds.), Örgüt kuramlarl, 77-132. Ankara: İmge Publishing.

Weber, M. ([1922] 1968). Economy and society: An interpretive sociology. New York: Bedminister Press.

Williamson, O. E. (1975). Markets and hierarchies: Analysis and antitrust implications. New York: Free Press. 